\title{
Gene Profiling of a Compatible Interaction Between Phytophthora infestans and Solanum tuberosum Suggests a Role for Carbonic Anhydrase
}

\author{
S. Restrepo, ${ }^{1}$ K. L. Myers, ${ }^{2}$ O. del Pozo, ${ }^{3}$ G. B. Martin, ${ }^{2,3}$ A. L. Hart, ${ }^{4}$ C. R. Buell, ${ }^{4}$ W. E. Fry, ${ }^{2}$ and \\ C. D. Smart ${ }^{1}$ \\ ${ }^{1}$ Department of Plant Pathology, Cornell University, Geneva, NY, U.S.A.; ${ }^{2}$ Department of Plant Pathology, Cornell University, \\ Ithaca, NY, U.S.A.; ${ }^{3}$ Boyce Thompson Institute for Plant Research, Ithaca, NY, U.S.A.; ${ }^{4}$ The Institute for Genomic Research, \\ 9712 Medical Center Drive, Rockville, MD, U.S.A.
}

Submitted 12 January 2005. Accepted 11 May 2005.

\begin{abstract}
Late blight of potato, caused by the oomycete pathogen Phytophthora infestans, is a devastating disease that can cause the rapid death of plants. To investigate the molecular basis of this compatible interaction, potato cDNA microarrays were utilized to identify genes that were differentially expressed in the host during a compatible interaction with $P$. infestans. Of the 7,680 cDNA clones represented on the array, $643(12.9 \%)$ were differentially expressed in infected plants as compared with mock-inoculated control plants. These genes were classified into eight groups using a nonhierarchical clustering method with two clusters (358 genes) generally down-regulated, three clusters (241 genes) generally up-regulated, and three clusters (44 genes) with a significant change in expression at only one timepoint. Three genes derived from two down-regulated clusters were evaluated further, using reverse transcription real-time polymerase chain reaction analysis. For these analyses, both incompatible and compatible interactions were included to determine if suppression of these genes was specific to compatibility. One gene, plastidic carbonic anhydrase (CA), was found to have a very different expression pattern in compatible vs. incompatible interactions. Virus-induced gene silencing was used to suppress expression of this gene in Nicotiana benthamiana. In CA-silenced plants, the pathogen grew more quickly, indicating that suppression of $\mathrm{CA}$ increases susceptibility to $P$. infestans.
\end{abstract}

Phytophthora infestans is the most devastating disease of potato world-wide, and host resistance is by far the most attractive method for control. Much is known about the incompatible interaction between potatoes and $P$. infestans, as host responses are quickly detectable and include generation of active oxygen species, a cascade of events associated with the hypersensitive response, and up-regulation of pathogenesisrelated genes (Avrova et al. 2004; Birch et al. 1999; Gebhardt and Valkonen 2001; Kolomiets et al. 2000; Vleeshouwers et al. 2000; Yoshioka et al. 1999). The result of incompatibility is containment of the pathogen and, at the "whole plant" level,

Corresponding author: C. D. Smart; E-mail: cds14@ cornell.edu

* The $\boldsymbol{e}$-Xtra logo stands for "electronic extra" and indicates the HTML abstract available on-line contains a supplemental table, listing the differentially expressed genes in each k-means cluster, not included in the print edition. the absence of disease. Clearly, these mechanisms are dramatically effective.

While the molecular mechanisms of compatibility between $P$. infestans and potato are not as well known as those of incompatibility, the infection process has been well-studied. Macro- and microscopic observations have provided a fairly complete phenotypic description of this hemibiotrophic interaction, but there have been relatively few studies of gene expression during the compatible interaction (Beyer et al. 2001; Dellagi et al. 2000). During the first several hours or days of the interaction, the pathogen grows well intercellularly and then intracellularly (Coffey and Wilson 1983). Within several days, the first cells involved in the interaction die. However, at the periphery of the lesion where the pathogen is consistently contacting additional cells, the necrotrophic phase is delayed. This leads to an expanding lesion, with a necrotrophic center and a biotrophic periphery. It is largely the biotrophic periphery that supports sporulation, enabling a continual and rapid population growth of $P$. infestans.

It seems probable that $P$. infestans not only delays the onset of host defenses but also suppresses them in the early part of the compatible interaction. In the 1980s, it was suggested that $P$. infestans produced cell-death inhibitory molecules and death-suppressing glucans (Doke et al. 1998; Yoshioka et al. 1999). In studies that have examined compatibility between potato and $P$. infestans, several genes related to programmed cell death have been shown to be induced much later than during an incompatible interaction (Avrova et al. 2004). However, some (but not all) epidermal cells do undergo a hypersensitive response (HR) in the first $24 \mathrm{~h}$ of a compatible interaction (Freytag et al. 1994; Vleeshouwers et al. 2000). Several genes with possible roles in defense and stress response have been shown to be up-regulated during both compatible and incompatible interactions (Beyer et al. 2001; Birch et al. 1999). Thus, compatibility appears to be a complex phenomenon not exclusively due to a specific single factor.

In addition to suppression of defense responses, a reduction in photosynthetic ability has been associated with the compatible potato late blight interaction. For example, a decrease in the efficiency of photosystem II was associated with the compatible interaction (Koch et al. 1994). In a separate study, reductions in chlorophyll-a fluorescence parameters were associated with susceptibility, and these decreases were not due to chlorophyll degradation (Schnabel et al. 1998). These results were also consistent with a modification of photosystem II. 
Data from other plant-pathogen systems indicate that suppression of carbonic anhydrase (CA) may play a role during incompatible interactions. This enzyme reversibly converts carbon dioxide to bicarbonate, has antioxidant activity, and is known to bind salicylic acid (SA) (Slaymaker et al. 2002). Suppression of this gene in Nicotiana benthamiana compromised the rapid cell death usually observed upon coexpression in plant leaves of the tomato Pto kinase and type III effector AvrPto genes (Slaymaker et al. 2002).

We have found that isolates of $P$. infestans common in the United States can cause disease on $N$. benthamiana (Becktell 2005; Smart et al. 2002). These isolates produce sporulating lesions on $N$. benthamiana in the lab and in the field. When exposed in the field to an epidemic on potatoes, $N$. benthamiana became increasingly diseased over time and the lesions sporulated during the same environmental conditions that supported sporulation on potatoes (Becktell 2005). Thus, it is possible to use $N$. benthamiana as an experimental host to dissect responses to $P$. infestans.

The goal of this study was to gain insight into the molecular basis of the compatible interaction between $P$. infestans and its hosts (with a major emphasis on the role of gene suppression). The approach was to first use potato microarrays containing 7,680 potato cDNA clones, generated from a large-scale potato expressed sequence tag (EST) project (Ronning et al. 2003), that represent approximately 5,000 unique sequences to provide a global view of gene expression over time during a compatible interaction. To determine if gene suppression was correlated with compatibility, reverse transcription real-time polymerase chain reaction (PCR) was used to compare gene expression patterns between compatible and incompatible interactions. One gene, plastidic CA, was found to have very different expression patterns during compatible vs. incompatible interactions. To gain a better understanding of the role CA may play in a compatible interaction, the gene was silenced in N. benthamiana, revealing that suppression of CA appears to promote host susceptibility. These results are discussed in the context of a possible general role of pathogen-induced gene suppression in host susceptibility.

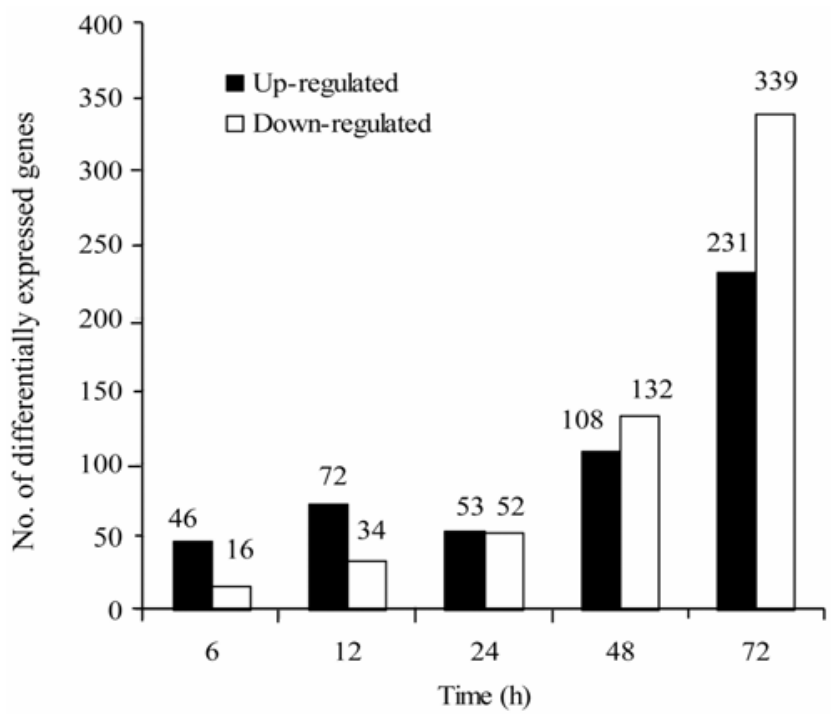

Fig. 1. Differential gene expression at five timepoints following inoculation of potato plants with a compatible strain of Phytophthora infestans, compared with mock-inoculated potato plants. Genes were determined to be differentially expressed if there was a $\geq 1.5$-fold change in their expression profiles during at least one timepoint in response to the inoculation with $P$. infestans.

\section{RESULTS}

$P$. infestans colonization of potato plants.

As expected, no symptoms of infection were observed on any of the potato plants (cultivar Kennebec) in the first $48 \mathrm{~h}$ following inoculation (Smart et al. 2003). Several small black lesions were seen on plants inoculated with $P$. infestans isolate US940480 three days after inoculation. By five days after inoculation, severe symptoms and pathogen sporulation were observed on all plants inoculated with US940480. No symptoms were observed on plants inoculated with US970001 throughout the course of the experiment. This was expected, since potato cultivar Kennebec contains the R1 gene that provides resistance against isolate US970001, resulting in an incompatible interaction. Likewise, no symptoms were observed on potato plants mock-inoculated with water (healthy control plants).

\section{Microarray expression analysis.}

In a first experiment necessary to determine microarray technical reproducibility, three self-self hybridizations were performed. In self-self hybridizations, the ideal result would be a Cy5/Cy3 signal ratio of 1.0 for each spot on the array, following data normalization. A two-standard deviation limit of 1.2 fold was observed in the self-self hybridizations, with $99.6 \%$ of the genes within 1.5 fold. Based on these results, only genes exhibiting a greater than 1.5 -fold change in the $\mathrm{Cy} 5 / \mathrm{Cy} 3$ ratio were considered biologically significant in this study. Using these parameters, a false detection rate lower than $1 \%$ for each timepoint was predicted. False detection rates were $0.26 \%$ for 6 h, 0.06 for 12 h, 0.05 for 24 h, 0.04 for 48 h, and 0.02 for $72 \mathrm{~h}$.

\section{A compatible potato-P. infestans interaction altered the mRNA levels of approximately $13 \%$ of the genes assayed.}

To increase the confidence with which the results could be interpreted, three biological replicates of the entire experiment were performed, with a technical replicate (two arrays) for each hybridization. Thus, results from six arrays were analyzed for each timepoint. A significant change in gene expression was reported only if the gene was identified using combined data from the three experiments. Analysis of the compatible potato- $P$. infestans interaction compared with mock-inoculated potato revealed significant differential expression during at least one timepoint for 643 of the 7,680 clones represented on the microarray (12.9\%). At 6 h, 46 genes were induced and 16 were repressed; at $12 \mathrm{~h}, 72$ genes were induced and 34 repressed; at 24 h, 53 genes were induced, 52 repressed; at $48 \mathrm{~h}$, 108 genes were induced and 132 repressed; at 72 h, 231 and 339 genes were induced and repressed, respectively (Fig. 1). Expression of many defense- and disease-responsive genes previously reported to be altered during the potato- $P$. infestans interaction were also identified in this study (Avrovra et al. 1999, 2004; Beyer et al. 2001; Birch et al. 1999; Smart et al. 2003). The entire data set (all data and images for each of the 33 arrays) is available at The Institute for Genomic Resources (TIGR) website.

\section{Cluster analysis of microarray data.}

In order to identify and detect genes with a modified expression pattern during the compatible interaction between potato and $P$. infestans, a clustering program was used to analyze the 643 differentially expressed genes. Eight clusters representing different patterns of regulation were identified. The eight clusters comprised 283, 52, 11, 26, 7, 77, 75, and 112 genes (Fig. 2).

Although eight clusters were defined, several clusters shared some common features. First, expression of genes in Clusters 
1 and 7 steadily declined as the infection proceeded. Second, Clusters 2, 6, and 8 contained genes whose expression increased steadily as the infection proceeded. The remaining clusters (3, 4, and 5) each contained genes whose expression changed as the infection proceeded and each had only one timepoint at which gene expression was significantly different from that in the mock-inoculated plants. Cluster 3 contained genes upregulated only at $12 \mathrm{~h}$; Cluster 4 contained genes down-regulated only at $12 \mathrm{~h}$; Cluster 5 contained genes down-regulated only at $6 \mathrm{~h}$ (Fig. 2). The following is a brief description of each cluster.

Cluster 1. This was the largest cluster, containing 283 genes, all of which were repressed throughout the timecourse of the experiment. The repression of the genes in this cluster started at $6 \mathrm{~h}$ after inoculation but only reached a 1.5 fold (biologically significant) decrease after $24 \mathrm{~h}$. Downregulation as a consequence of the $P$. infestans compatible interaction was observed for genes encoding proteins involved in photosynthesis and cell maintenance. These included chlorophyll $a / b$ binding protein, photosystem I subunits $\mathrm{N}$ and XI, photosystem II subunit W, ferredoxin reductase, phosphoglycerate kinase, glyceraldehyde-3-phosphate dehydrogenase, aspartate kinase, acyl CoA synthase, and CA. Several defense-related genes were also present in Cluster 1 including omega- 6 fatty acid desaturase, peroxidase, superoxide dismutase, peroxiredoxin, 2-cys-peroxiredoxin, proteinase inhibitor I, and proteinase inhibitor II.

Cluster 2. The 52 genes in this cluster were induced and reached a 1.5-fold increase in expression at 48 and $72 \mathrm{~h}$. Several defense-related genes were grouped in this cluster, including catalase, polyphenol oxidase, endochitinase, basic glucanase, thaumatin-like protein, cysteine protease, and calreticulum.

Cluster 3. Genes in Cluster 3 had a transient 1.5 -fold increase in expression $12 \mathrm{~h}$ after inoculation. The 11 genes in this cluster included alcohol dehydrogenase, glutathione transferase, and several EST sequences of unknown function.

Cluster 4. In contrast to genes in Cluster 3, the 26 genes in Cluster 4 showed a significant repression between 12 and $24 \mathrm{~h}$ after inoculation. Genes encoding adenosylmethionine synthetase and a proline-rich protein were clustered in this group, in addition to several EST sequences with unknown function.

Cluster 5. Only seven genes grouped in Cluster 5, which had an expression pattern of repression at $6 \mathrm{~h}$ followed by induction at 12 to $24 \mathrm{~h}$ after inoculation. Several members of this cluster were a transcription elongation factor, an NADPH oxidase-like gene, and a guanine nucleotide exchange factor.

Cluster 6. The 77 genes in this cluster were up-regulated by more than 1.5-fold at all timepoints after inoculation. Many defense-related genes were grouped in this cluster. These included lipoxygenase, osmotin, glucanase, chitinase, peroxidase, catechol oxidase, polyphenol oxidase, and glutathione reductase.

Cluster 7. The genes in this cluster were weakly upregulated at 6 and $12 \mathrm{~h}$ after inoculation (below 1.5-fold increase), and by $72 \mathrm{~h}$ after inoculation, they were significantly repressed. Among the 75 genes were two types of proteinase inhibitors, cysteine and aspartic. Additionally, 2oxoglutarate-dependent dioxygenase (2-ODD) and several genes encoding brassinosteroid biosynthesis proteins were in this cluster.

Cluster 8. All genes in this cluster were up-regulated at all timepoints after inoculation with a compatible strain of $P$. infestans but only reached the 1.5-fold threshold after $48 \mathrm{~h}$. Defense-related genes were found in this cluster, including peroxidase, catalase isozyme 2 , and glutathione peroxidase. The gene coding for the cathepsin B protease (a cysteine protease) also clustered in this group.

\section{Real-time quantitative (rtq) PCR analysis.}

To determine if gene suppression identified in the microarray experiments was unique to compatible interactions or if this suppression also occurred during an incompatible interaction, reverse transcription rtq-PCR was utilized (Table 1). Because Clusters 1 and 7 showed the greatest level of suppression during the compatible interaction, two genes from Cluster 1 and one gene from Cluster 7 were chosen for comparison with the incompatible interaction, using rtq-PCR. The expression patterns of 2-ODD, the jasmonic acid responsive proteinase inhibitor II (PinII), and plastidic CA were all followed over time.

The rtq-PCR results for 2-ODD (Cluster 7) show no significant change in gene expression for either the compatible or incompatible interaction when compared with RNA from mock-inoculated tissue from 6 to $48 \mathrm{~h}$ after inoculation. There was, however, a decrease in mRNA levels in the compatible interaction at $72 \mathrm{~h}$ after inoculation that was not seen during the incompatible interaction (Fig. 3).

Similar results were observed in rtq-PCR experiments following the expression pattern of the PinII gene (Cluster 1). From 6 to $24 \mathrm{~h}$ after inoculation, the compatible, incompatible and mock-inoculated samples were not significantly different. At $48 \mathrm{~h}$, both the compatible and incompatible interactions

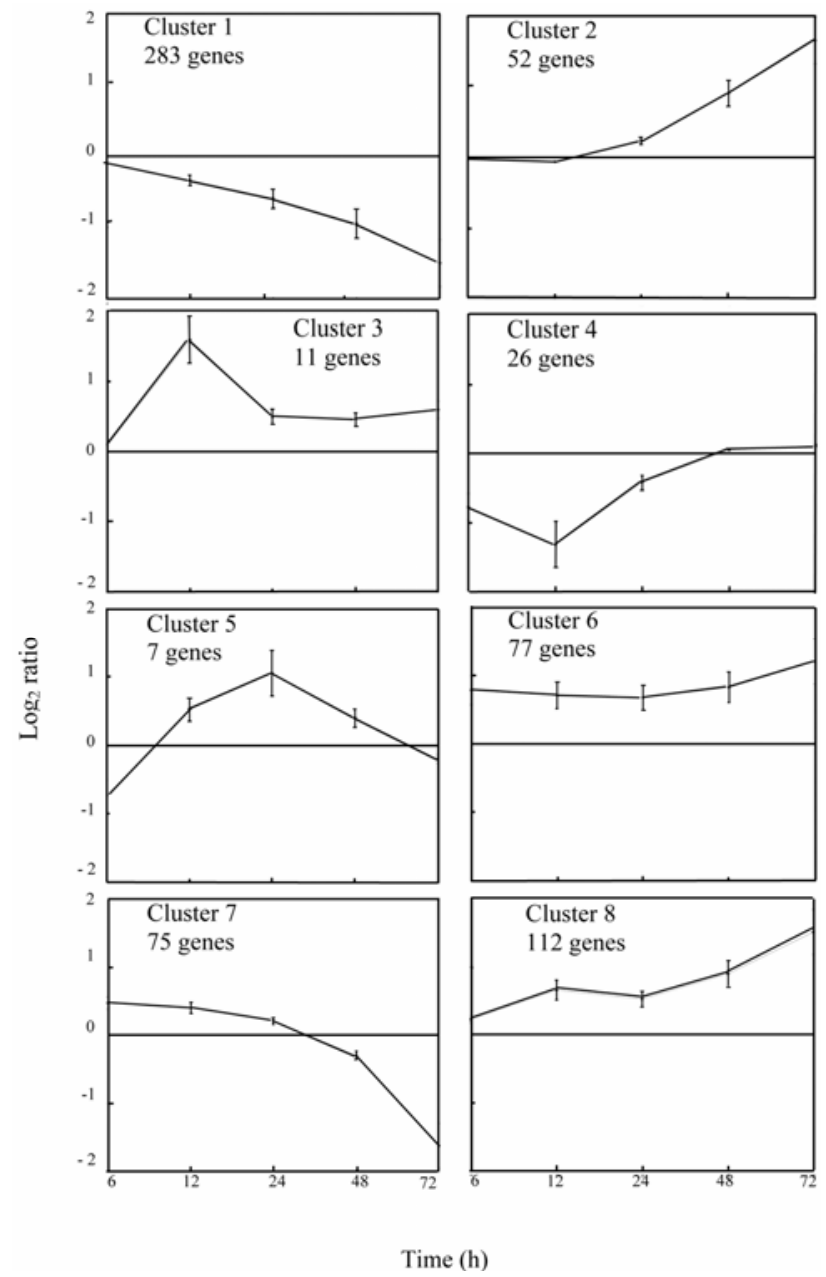

Fig. 2. Nonhierarchical cluster analysis (k-means, eight clusters) of expression profiles for 643 potato genes. Each gene had a $\geq 1.5$-fold change in expression during at least one timepoint in response to inoculation with Phytophthora infestans relative to mock-inoculated plants. The mean of the gene expression patterns of each cluster is represented by plotting the $\log _{2}$ value of the expression ratio versus time. Error bars represent the standard deviation of the gene expression ratio for each cluster at each timepoint. 
showed a slight decrease in PinII mRNA levels. By $72 \mathrm{~h}$ after inoculation, the incompatible interaction had returned to mock-inoculated levels (represented as 1 on the relative transcript change scale), while the compatible interaction had significantly repressed levels (Fig. 3).

The plastidic CA gene from microarray Cluster 7 exhibited the most drastic change in expression, with levels in the compatible interaction significantly different from the mockinoculated control at $6 \mathrm{~h}$ after inoculation. A large difference in levels of CA mRNA between the compatible and incompatible interactions was observed at $12 \mathrm{~h}$ after inoculation with the incompatible interaction showing upregulation of the gene, while there was severe repression at the same time in the compatible interaction. At 24 and $48 \mathrm{~h}$, both compatible and incompatible interactions were significantly repressed. Interestingly, by $72 \mathrm{~h}$ after inoculation expression levels in the compatible interaction remained undetectable, while levels were increasing in the incompatible interaction (Fig. 3).

\section{Potato virus X (PVX)-mediated gene silencing of CA enhances susceptibility.}

To determine the role of CA in susceptibility, we utilized $N$. benthamiana, which in our hands, is a host of P. infestans (Fig. 4). The interaction between $N$. benthamiana and isolate US970001 is a genetically compatible interaction that leads to the death of the plant even in wild-type plants that have not been subjected to gene silencing (Fig. 4). The two PVX-vector clones used for silencing in this study (30B10 and30C84) had been used to silence CA in $N$. benthamiana in a previous study but were sequenced to confirm identity as CA (GenBank accession numbers AY974606 and AY974607, respectively). Regions of the CA gene covered by these partial cDNA clones are shown in Figure 5A.

Reverse transcriptase (RT)-PCR was used to confirm that PVX constructs carrying the CA gene were successful in silencing CA (Fig. 5B). Silencing did not lead to a complete knockout of the gene, as RT-PCR for CA was first performed using 35 cycles with no visible amplification product but was then performed using 45 cycles and a product was visible (Fig. 5B). An amplification product was visible in empty vector control plants at both 35 and 45 cycles (Fig. 5B). RT-PCR of the $N$. benthamiana actin gene, included as an equal loading control, remained unchanged (Fig. 5C). Plants silenced for CA showed typical PVX symptoms including mosaic symptoms and slight crinkling of leaves. Symptoms on CA-silenced plants were similar to those seen on empty vector control plants.
Rtq-PCR was used to quantify $P$. infestans in $N$. benthamiana plants at $96 \mathrm{~h}$ after inoculation. This timepoint was chosen so that increased growth of the pathogen early in the infection process (prior to symptom development) could be identified (Fig. 6). Because N. benthamiana is quite susceptible to $P$. infestans, all detached leaflets become diseased and show symptoms about 7 days after inoculation (Fig. 6). Silencing of CA resulted in greater susceptibility of $N$. benthamiana to P. infestans, based on a statistically larger quantity of pathogen internal transcribed spacer (ITS) RNA present in silenced plants compared with that of empty vector control plants (Fig. 5D). Analysis of variance showed that the differences in $P$. infestans quantification were statistically significant $(P=0.02)$. Based on the mean separation, the $P$. infestans ITS RNA levels in control plants inoculated with a vector lacking the CA gene were statistically lower than in plants silenced for CA.

\section{DISCUSSION}

In order to gain a better understanding of the potato- $P$. infestans compatible interaction, microarray experiments were performed to assess the transcriptional profile over a 72-h infection period. Approximately $13 \%$ of the genes on the array were found to be differentially expressed when compared with mockinoculated, healthy potato tissue. The number of differentially expressed genes increased with time. During the early timepoints (6 and $12 \mathrm{~h}$ after inoculation), a majority of differentially expressed genes were induced, while at the later timepoints (48 and $72 \mathrm{~h}$ after inoculation), more genes were repressed than induced (Fig. 1). Surprisingly, these results differ from those observed by Moy and associates (2004) in a study examining expression profiles in soybean during a compatible interaction with Phytophthora sojae, in which they found a larger number of genes up-regulated at all timepoints (Moy et al. 2004). The reason for a greater level of suppression in the potato- $P$. infestans interaction is unknown but may be clarified as larger arrays with a greater percentage of the plant genome are utilized.

The majority of up-regulated genes in the potato- $P$. infestans interaction were plant defense genes and were grouped into three clusters (Fig. 2). While 77 of these were up-regulated at all timepoints (Cluster 6), 164 genes (Clusters 2 and 8) were significantly up-regulated only after $48 \mathrm{~h}$ postinoculation. While many defense-related genes were up-regulated, others were not (Table 2).

Of particular interest was the suppression of genes involved in the jasmonic acid (JA) defense pathway. An enzyme required for

Table 1. Primer and probe sequences used for real-time quantitative PCR

\begin{tabular}{ll}
\hline Gene name & \multicolumn{1}{c}{ Primer and probe sequence $\left(\mathbf{5}^{\prime}\right.$ to $\left.\mathbf{3}^{\prime}\right)$} \\
\hline Potato actin & Forward CCAGTGGCCGTACAAGAGGTA \\
& Reverse AGCCTTCATAAATTGGCACTGTAT \\
Potato carbonic anhydrase & Probe FAM- TGCTGGATTCTGGTGATGGGTGTCA-TAMRA \\
& Forward AGTGTGCCCATCCCATGTTC \\
Potato 2-oxoglutarate-dependent dioxygenase & Reverse CCATGTTGGCGATGTTACGA \\
& Probe FAM -ACTTCCAACCCGGTGAGGCATT- TAMRA \\
& Forward AGCAGCGCTAAGCATTATGATTC \\
Potato proteinase inhibitor II & Reverse TCCCATCAAGATTGCAGCTAT \\
& Probe FAM-AGGAGCATCGTTACTGGAGAGATGTCTTGGA-TAM \\
Phytophthora infestans internal transcribed spacer region & Forward CAAGCGATTTCGAACATGCA \\
& Reverse AATATGGGCAAATCCCATAGTCA \\
& Probe FAM- ACGCCAAAGCTTGGACCAAAGAAAGTG- TAM \\
Nicotiana benthamiana actin & Forward CTGGTTGTGGACGCTGCTATT \\
& Reverse AATCGAGCATTTCTCCATTAA \\
& Probe TET- TAGCGAGTTGGCGACCGGTTGTCT- TAMRA \\
& Forward CGAGCTGCCTGATGGACAA \\
& Reverse AGCTTCCATTCCGATCATTGA \\
& Probe FAM-CACCATTGGTGCTGAGAGATTCCGC-TAMRA \\
\hline
\end{tabular}


JA biosynthesis, omega-6 fatty acid desaturase (Jin et al. 2001), was down-regulated, as were several proteinase inhibitors. Similar results were recently observed for the soybean- $P$. sojae interaction (Moy et al. 2004). Several previous studies have shown that the JA defense response pathway was not induced in a host plant upon infection with $P$. infestans (Fidantsef et al. 1999; Smart et al. 2003), however, this is the first report showing that this pathway is down-regulated in potato during a compatible interaction. The evidence for suppression of this pathway is based on indirect evidence (reduced expression of marker genes), and additional studies are necessary to confirm these data.
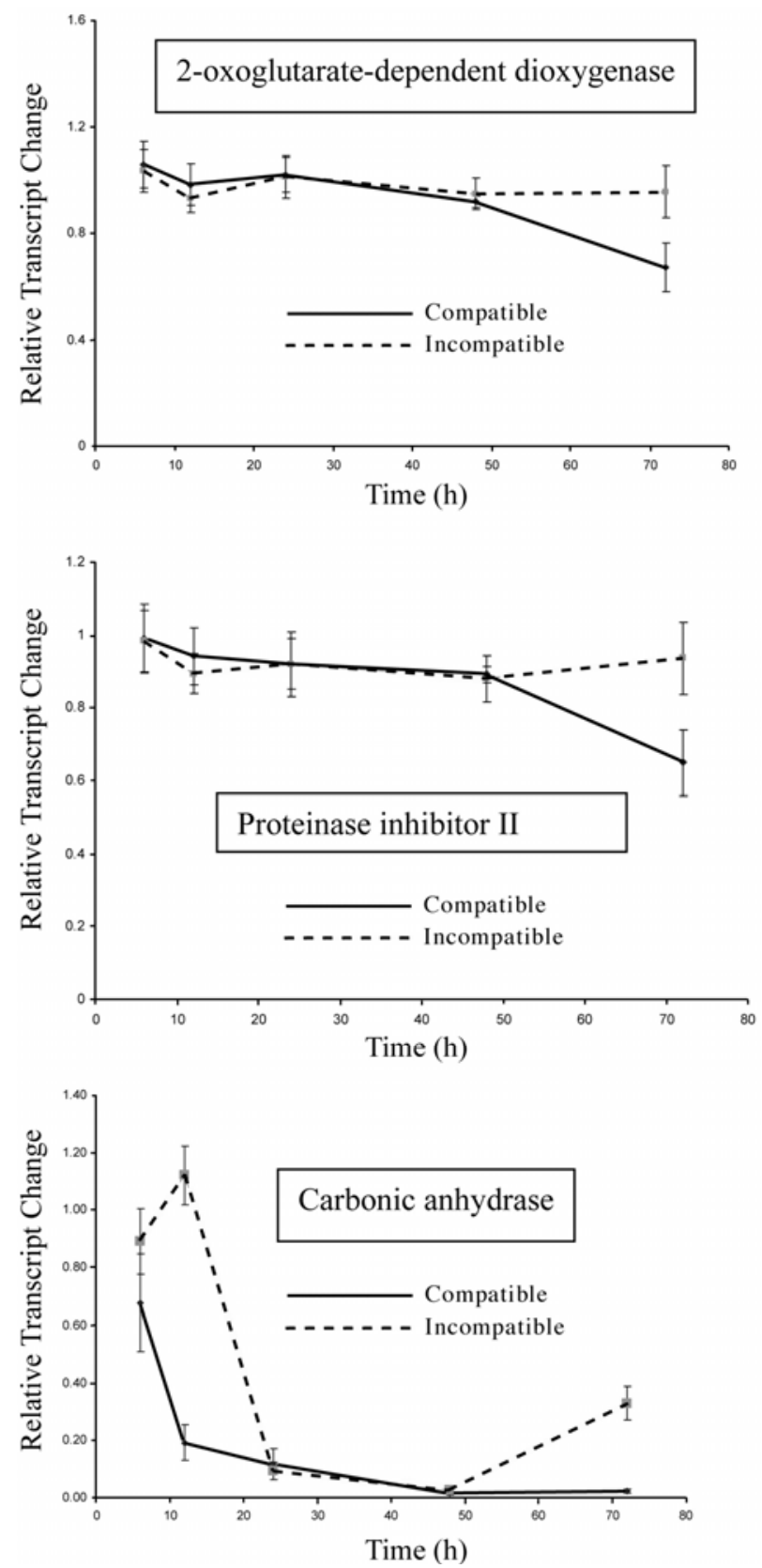

Fig. 3. Reverse transcriptase real-time polymerase chain reaction analyses of three potato genes, following inoculation with compatible or incompatible isolates of Phytophthora infestans. Top, middle, and bottom panels show relative transcript change for 2-oxoglutarate-dependent dioxygenase, proteinase inhibitor II, and carbonic anhydrase, respectively. Transcript levels were calculated using the standard curve method from triplicate data, with the potato actin gene as an internal control and mock-inoculated tissue as a reference sample. Results represent the mean fold change of the transcript level over mock-inoculated healthy tissue, referred as the $1 \times$ expression level.
The largest group of genes suppressed during the compatible interaction were photosynthesis-related. Transcriptional downregulation of photosynthesis-related genes has previously been reported for incompatible interactions (Gibly et al. 2004; Mysore et al. 2002; Schenk et al. 2000) as well as the compatible interaction between soybean and P. sojae (Moy et al. 2004). When looking at $P$. infestans interactions, one study found that photosynthesis-related genes were down-regulated when the HR elicitor INF1 (isolated from $P$. infestans) was infiltrated into a $N$. benthamiana leaf (Matsumura et al. 2003). It was hypothesized that, in $N$. benthamiana upon infiltration with INF1, photosystem II activity was lost, which caused reactive oxygen species accumulation in the chloroplast and induced HR in the leaf tissue (Matsumura et al. 2003). In a separate study on nonhost resistance in Arabidopsis to $P$. infestans, photosynthesis-related gene expression was not reported to be down-regulated (Huitema et al. 2003). In the current study, the downregulation of photosynthesis-related genes started at $6 \mathrm{~h}$ after inoculation but only reached a 1.5 -fold decrease after $24 \mathrm{~h}$. These results agree with earlier studies that found a reduction in chlorophyll, a fluorescence during the compatible interaction, which was related to a decrease in photosynthetic electron-transport (Koch et al. 1994; Schnabel et al. 1998). The reason for the reduction in photosynthesis during the compatible interaction between potato and $P$. infestans is currently unknown.

The most rapid and severe downregulation was seen for the plastidic CA gene. This gene encodes an enzyme responsible for the reversible hydration of carbon dioxide to bicarbonate and provides carbon dioxide for carboxylation by rubisco. In $\mathrm{C}_{3}$ plants such as potato, $\mathrm{CA}$ is located in the chloroplast stroma and can represent $2 \%$ of the total protein in leaf tissue (Burnell 2000). In other expression profiling experiments, CA was found to be down-regulated in tomato plants following application of the fungal toxin fusicoccin (Frick and Schaller 2002) and also down-regulated in Arabidopsis following application of methyl jasmonate (Schenk et al. 2000). CA has been

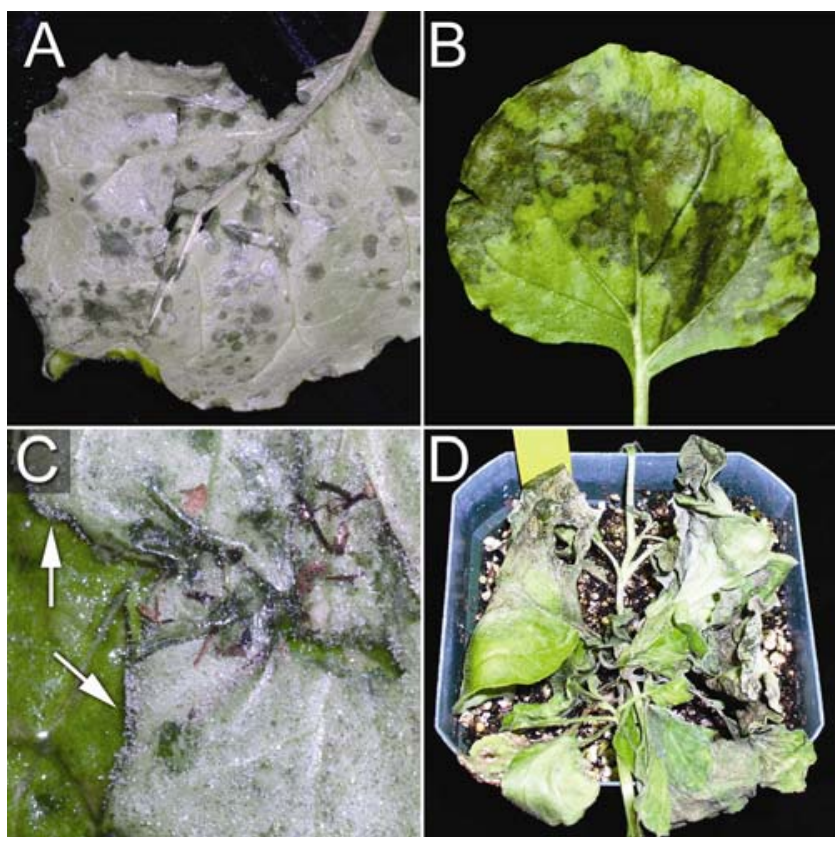

Fig. 4. Symptoms seen on wild-type Nicotiana benthamiana following inoculation with Phytophthora infestans. A, Visible water-soaked lesions first appear on the abaxial leaf surface 5 to 7 days after inoculation. B, Expanding necrotic lesions occur on the adaxial leaf surface 8 to 10 days after inoculation. C, Pathogen sporulation is visible on the abaxial leaf surface by 10 days after inoculation (arrows point to sporangia). D, $N$. benthamiana plant killed by P. infestans, two weeks after inoculation. 
shown to have antioxidant activity and is known to bind SA (Slaymaker et al. 2002).

To determine if suppression of certain genes was correlated with compatibility, reverse transcription rtq-PCR was utilized to follow the expression pattern of three genes during mockinoculated, compatible, and incompatible interactions. The three genes were 2-ODD, proteinase inhibitor II PinII, and CA. No photosynthesis-related genes were used for rtq-PCR because of the significant number of previous studies that examined the downregulation of these genes (as discussed above).

The 2-ODD gene was chosen for rtq-PCR because the gene product belongs to a well-studied family of enzymes (Hausinger 2004) and the role in defense is not yet clear. The EST identi-
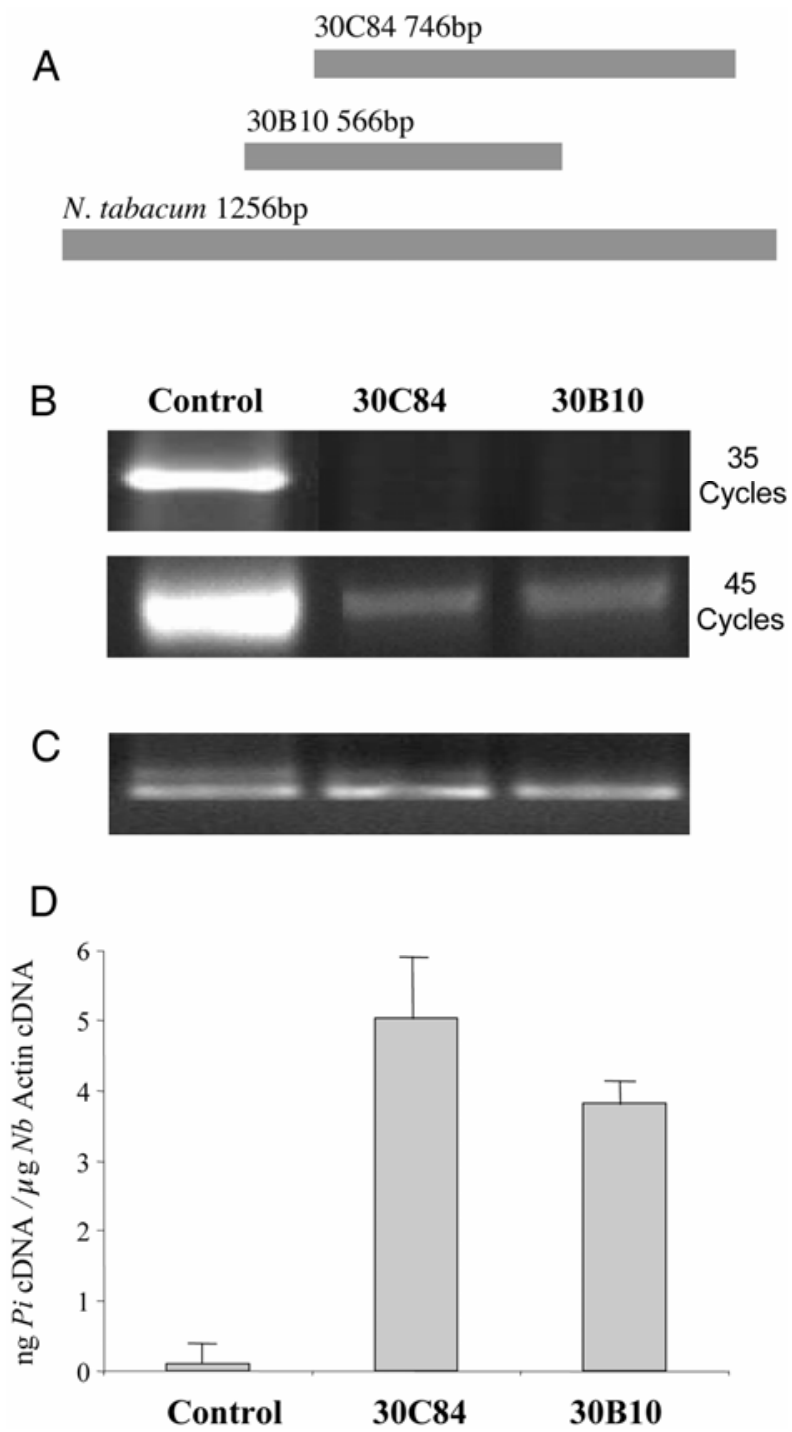

Fig. 5. Potato virus $X$-mediated silencing of carbonic anhydrase (CA) gene expression in Nicotiana benthamiana was correlated with enhanced susceptibility to Phytophthora infestans. A, Schematic representation of $N$. benthamiana plastidic CA partial cDNA clones 30C84 and 30B10, used in gene-silencing experiments, compared with the full-length $N$. tabacum clone. B, Reverse transcription polymerase chain reaction (PCR) amplifycation of CA in $N$. benthamiana leaves showed reduced expression after silencing with cDNA clones 30C84 and 30B10, compared with the empty vector control. The PCR cycle number is indicated to the right of the ethidium bromide-stained agarose images. C, Reverse transcription PCR amplification of actin demonstrated equal amounts of cDNA, using 35 cycles. D, Reverse transcription Real-time quantitativePCR of $P$. infestans DNA in control and silenced $N$. benthamiana leaves $96 \mathrm{~h}$ after inoculation with the pathogen, showing higher levels of pathogen DNA in silenced plants. fied in this study was most similar to the Solanum chacoense 2-ODD that is up-regulated during pollination and is induced by both methyl jasmonate and SA (Lantin et al. 1999). Additionally, other 2-ODDs are known to be involved in flavone biosynthesis and production of antimicrobial compounds (Hausinger 2004). The 2-ODD identified in this study was down-regulated (grouped with Cluster 7) during the compatible interaction in microarray analyses (Fig. 2). Rtq-PCR results did confirm a suppression of 2-ODD in the compatible interaction at $72 \mathrm{~h}$ after inoculation that was not seen during the incompatible interaction (Fig. 3). The reason for suppression during compatible interactions is unknown but may be related to the overall suppression of the JA defense response pathway.

The relative gene expression profile detected by rtq-PCR of PinII in the compatible and incompatible interactions was similar to that observed for 2-ODD. This proteinase inhibitor is commonly used as a marker for the JA defense response pathway (Fidantsef et al. 1999; Smart et al. 2003) and was grouped with Cluster 1 in microarray analyses (Fig. 2). The downregulation of PinII over time, with a significant suppression at $72 \mathrm{~h}$ observed in rtq-PCR, mirrors the results obtained using microarrays. The fact that there is significant downregulation in the compatible interaction but not in the incompatible interaction at $72 \mathrm{~h}$ after inoculation validates

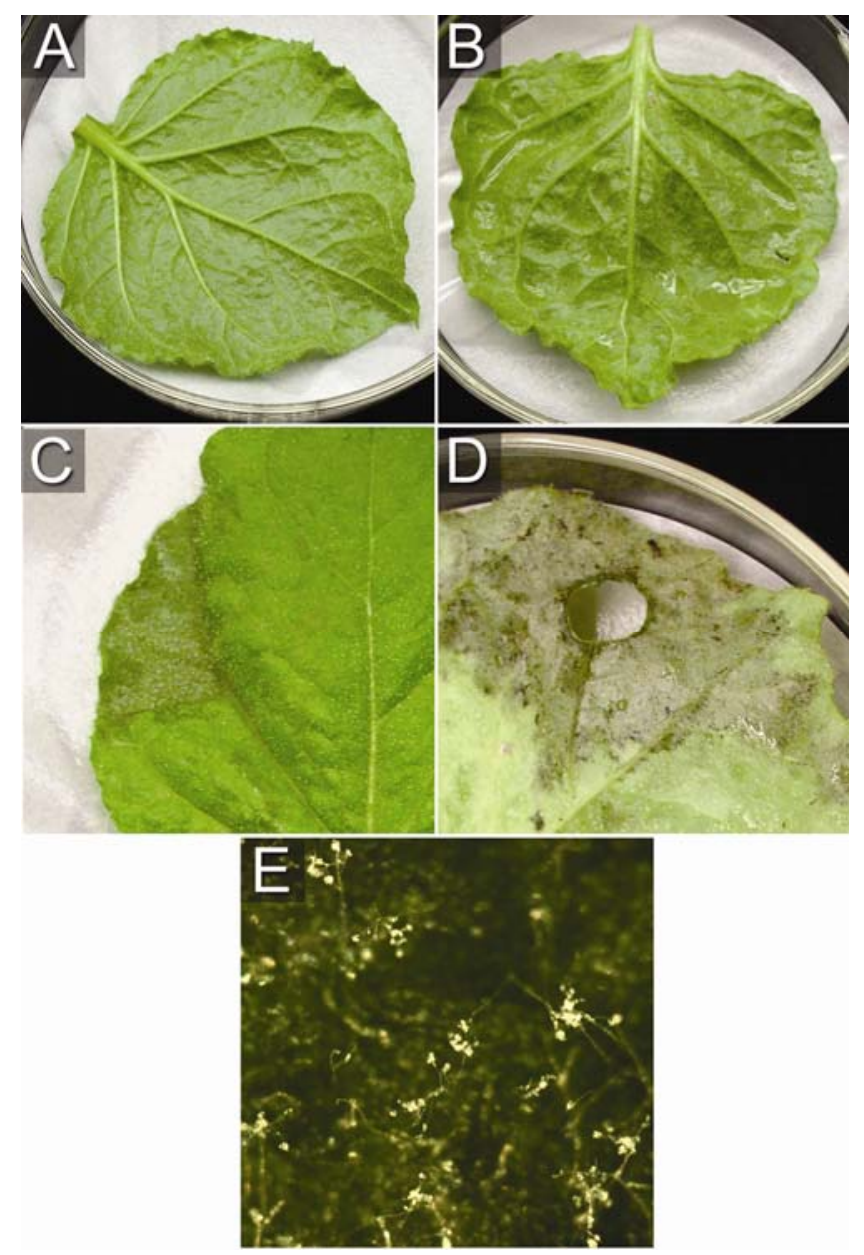

Fig. 6. Detached leaves of Nicotiana benthamiana control and carbonic anhydrase (CA)-silenced plants following inoculation with Phytophthora infestans. Detached leaves of $\mathbf{A}$, empty vector control plant and $\mathbf{B}, \mathbf{C A}-$ silenced plant (construct 30C84), $96 \mathrm{~h}$ after inoculation. No symptoms can be seen at this early stage of infection. P. infestans lesions on $\mathbf{C}$, empty vector control and D, CA-silenced leaf, 7 days after inoculation. E, Sporulation of $P$. infestans on CA-silenced leaf. 
the hypothesis that the JA defense response pathway is suppressed during the compatible interaction between potato and P. infestans (Fig. 3).

The differential expression profiles revealed by rtq-PCR for $\mathrm{CA}$ at $12 \mathrm{~h}$ after inoculation were intriguing. The upregulation of $\mathrm{CA}$ at this early timepoint during the incompatible interaction compared with the downregulation during the compatible interaction clearly differentiates resistant from susceptible. Equally remarkable was the fact that CA was barely detectible in either interaction at 24 and $48 \mathrm{~h}$ after inoculation, followed by induction at $72 \mathrm{~h}$ in only the incompatible interaction (Fig. 3). While CA was impaired for a short period in resistant plants, it recovered quite quickly.

$P$. infestans grew more readily in $N$. benthamiana plants silenced for CA than in control plants (Fig. 5). This is consistent with the hypothesis that suppression of CA enhances susceptibility. The variability in pathogen growth on plants silenced with CA clone $30 \mathrm{C} 84$ versus 30B10 could be due to nonuniform infection, since leaf disks were utilized in this assay. In a previous study, silencing of CA in $N$. benthamiana resulted in the suppression of $\mathrm{HR}$, induced by the coexpression of the tomato resistance gene Pto and the Pseudomonas syringae pv. tomato avirulence gene avrPto, in $45 \%$ of the infiltrations (Slaymaker et al. 2002). Many P. infestans isolates from the Cornell University Phytophthora collection were tested, and all were found to establish a compatible interaction with $N$. benthamiana. Thus, it was not possible to determine if CA plays a role in suppression of HR during an incompatible interaction.

While CA is located in the chloroplast stroma, it does not appear to have a role in photosynthesis under optimal growth conditions, as reductions in CA levels by $90 \%$ in tobacco had no phenotypic effect (Price et al. 1994). It is possible that suppression of CA could impact photosynthesis under stressful conditions, including biotic stress such as infection by $P$. infestans. Recent studies show a role for CA in plant lipid biosynthesis, because a reduction of CA activity decreases the rate of lipid biosynthesis (Hoang and Chapman 2002). If downregulation of CA transcript level observed in the current study can be correlated with reduced CA activity, this could cause a reduction in fatty acid biosynthesis that could explain the suppression of genes in the JA defense response pathway seen in the compatible interaction. In a previous study, no difference was observed in late blight disease severity between wild-type tomato cv. Castlemart and the def- 1 mutant, which has a reduced ability to accumulate jasmonic acid (Smart et al. 2003). These results were based on final disease severity and may differ from the results of this study, which followed the early infection process.

Future studies will examine both the cause of the rapid suppression of CA as well as the chain of events that lead to enhanced susceptibility following the silencing of this gene. It will be important to determine if there is a connection between suppression of $\mathrm{CA}$ and the overall downregulation of the JA defense response pathway. Additionally, we will attempt to differentiate genes that are directly suppressed upon pathogen attack from those that are secondary responses. The identification of primary suppression targets may lead to the development of potatoes that are less susceptible to late blight.

\section{MATERIALS AND METHODS}

\section{Plants, pathogen isolates, and inoculations.}

Four-week-old Solanum tuberosum plants (cv. Kennebec) were randomly sorted into three groups of 20 plants each. One day prior to inoculation, all 60 plants were placed into a humid chamber with a 16-h light period, $12 \mathrm{~h}$ per day of $100 \%$ relative humidity, and a temperature of $15^{\circ} \mathrm{C}$. One group of 20 plants was inoculated with $P$. infestans isolate US940480 (ATCC 208834, a member of the US-8 clonal lineage), the second group of 20 plants was inoculated with isolate US970001 (ATCC MYA-2350, a member of the US17 clonal lineage), and the final group was sprayed with water (the mock-inoculated control). Inoculations were made with a sporangial suspension $(20,000 / \mathrm{ml})$, and plants were sprayed until run-off, as previously described (Smart et al. 1998). These $P$. infestans isolates were chosen because isolate US940480 results in a compatible interaction when inoculated on cv. Kennebec (which carries the R1 gene), while US970001 results in an incompatible interaction. Additionally, these isolates have been well-studied both in the field and laboratory (Goodwin et al. 1998; Smart et al. 2003). Compatible interaction and mock-inoculated tissue from each timepoint (discussed below) was used in microarray experiments, while compatible, mock-inoculated, and incompatible interaction tissues were utilized in real-time PCR comparative experiments.

Tissue (all leaflets) from three plants per group was collected at six timepoints $(0,6,12,24,48$, and $72 \mathrm{~h}$ after inoculation). The leaflets for each treatment at each timepoint were pooled, were flash frozen in liquid nitrogen, and were stored at $-80^{\circ} \mathrm{C}$. After the 72 -h timepoint, there were two plants left from each group (compatible, incompatible, and

Table 2. Defense-related gene expression profiles during the potato-Phytophthora infestans compatible interaction ${ }^{\mathrm{a}}$

\begin{tabular}{|c|c|c|c|c|c|c|}
\hline \multirow[b]{2}{*}{ Gene name } & \multirow[b]{2}{*}{ EST accession number } & \multicolumn{5}{|c|}{ Fold change $^{b}$} \\
\hline & & $6 \mathrm{~h}$ & $12 \mathrm{~h}$ & $24 \mathrm{~h}$ & $48 \mathrm{~h}$ & $72 \mathrm{~h}$ \\
\hline Carbonic anhydrase & BQ113997 & 0.6 & 0.6 & 0.5 & 0.3 & 0.3 \\
\hline Proteinase inhibitor II & BQ113673 & 0.9 & 1.1 & 0.5 & 0.5 & 0.4 \\
\hline Peroxiredoxin (thioredoxin peroxidase) & BQ120178 & 1.0 & 0.8 & 0.7 & 0.7 & 0.7 \\
\hline 2-Cys peroxiredoxin & BQ113536 & 1.0 & 0.9 & 0.6 & 0.6 & 0.5 \\
\hline Proteinase Inhibitor I & BQ113590 & 1.0 & 0.9 & 0.6 & 0.9 & 0.6 \\
\hline Superoxide dismutase & BQ115156 & 0.9 & 0.8 & 0.8 & 0.7 & 0.7 \\
\hline Peroxidase & BQ121927 & 0.8 & 0.9 & 0.9 & 0.8 & 0.6 \\
\hline Aspartic proteinase inhibitor & BQ113896 & 1.7 & 1.0 & 1.2 & 1.1 & 0.7 \\
\hline Cysteine proteinase inhibitor & BQ114671 & 1.5 & 1.9 & 1.1 & 1.2 & 0.6 \\
\hline Cysteine protease & BQ112770 & 1.0 & 1.4 & 1.3 & 1.4 & 2.0 \\
\hline Peroxidase & BQ112873 & 1.2 & 1.3 & 1.3 & 1.4 & 2.5 \\
\hline Catechol oxidase & BQ118367 & 1.5 & 2.4 & 1.4 & 1.8 & 2.5 \\
\hline Catalase & BQ111810 & 1.4 & 1.7 & 1.9 & 2.3 & 3.3 \\
\hline Glutathione reductase & BQ117670 & 1.8 & 1.8 & 1.6 & 2.3 & 3.0 \\
\hline
\end{tabular}

${ }^{\mathrm{a}}$ Ratios greater than 1.5 (induction) are in bold and ratios lower than 1.5 (repression) are in bold italic font.

${ }^{\mathrm{b}}$ Fold change in expression expressed as Cy3/Cy5 ratio where Cy3 corresponded to inoculated tissue and Cy5 to mock-inoculated tissue at each timepoint. Ratios in bold and bold italic represent significant induction or repression. 
mock-inoculated). These plants were kept in the humid chamber for an additional 7 days to ensure that plants inoculated with a compatible isolate became fully diseased, while those inoculated with an incompatible isolate or mock-inoculated with water remained healthy. The entire experiment was repeated three times.

\section{Potato RNA isolation and preparation of array probes.}

Frozen plant tissues were ground, using a cold mortar and a pestle. Total potato leaf RNA was extracted using the hotphenol protocol (Perry and Francki 1992) as modified by $\mathrm{Gu}$ and associates (2000). Two RNA extractions of each pool (from each timepoint) were done. The RNA was precipitated, pooled, and stored at $-80^{\circ} \mathrm{C}$.

For each array hybridization, cDNA was generated from total RNA $(150 \mu \mathrm{g})$ isolated from mock-inoculated potato leaves and from leaves inoculated with US940480 (a compatible interaction). cDNA from mock-inoculated plants was labeled with one cyanine fluorophore (Cy3 or $\mathrm{Cy} 5)$, while cDNA from the compatible interaction was labeled with the other. All protocols used to generate and label cDNA were as described by Hedge and associates (2000). In the self-self hybridizations, three RNA samples ( $0 \mathrm{~h}$, mock-inoculated tissue) were split into two identical aliquots. Two populations of single-stranded cDNA were generated from the two aliquots and labeled with $\mathrm{Cy} 3$ or Cy5 fluorophores.

\section{Microarray hybridization and scanning.}

The 7,680-clone potato cDNA array (with each element spotted twice) generated by TIGR was used in these experiments. The clones were selected from EST sequences that were generated from a series of potato cDNA libraries used in the NSF potato EST sequencing project (Ronning et al. 2003). All clones were validated through resequencing and agarose gel electrophoresis prior to printing, to confirm the sequence of the clone and the presence of an insert. All data on the EST sequences, the clones on the array, and annotation of the clones can be found at the TIGR website. Two general sets of experiments were performed. The first set of experiments was the self-self hybridizations used to establish confidence levels. Three arrays were used and probed with cDNA generated from RNA samples that were split into two identical aliquots. The second set of experiments was the expression analysis during the compatible interaction. Arrays were probed with mockinoculated vs. infected potato tissue (compatible interaction) at each timepoint. Two arrays per timepoint (with five timepoints) were used for each of the three biological replicates, for a total of 30 arrays.

Arrays were prehybridized in order to block nonspecific background during hybridization. Slides were blocked in $5 \times$ $\mathrm{SSC}(1 \times \mathrm{SSC}$ is $0.15 \mathrm{M} \mathrm{NaCl}$ plus $0.015 \mathrm{M}$ sodium citrate), $0.1 \%$ sodium dodecyl sulfate (SDS), and $1 \%$ bovine serum albumin at $42^{\circ} \mathrm{C}$ for $45 \mathrm{~min}$ (Hedge et al. 2000). Slides were washed in sterile distilled water, followed by isopropanol, and were dried. Cy-3 and Cy-5 probes were combined, placed on the slide, and covered using a glass cover slip washed in $1 \%$ SDS. Arrays were put into hybridization chambers (Corning Inc., Corning, NY, U.S.A.) and were hybridized overnight at $42^{\circ} \mathrm{C}$ in a water bath. The slides were removed from the chambers and washed first in $2 \times \mathrm{SSC}$, $0.1 \% \mathrm{SDS}$ at $42^{\circ} \mathrm{C}$ for $5 \mathrm{~min}$., then in $0.1 \times \mathrm{SSC}, 0.1 \% \mathrm{SDS}$ at room temperature for $5 \mathrm{~min}$., and finally twice in $0.1 \times$ SCC at room temperature for $5 \mathrm{~min}$., and then were dried. Slides were scanned using an Axon GenePix 4100 microarray scanner (Axon Instruments Inc., Union City, CA, U.S.A.). The photomultiplier settings were adjusted in each channel to result in nonsaturation of the most highly expressed genes.
Array data analysis.

To determine fluorescence and background intensity, 16-bit scanned TIFF images were analyzed using GenePix Pro version 4.1 software (Axon Instruments Inc.). The median pixel intensity within a given spot was used as the signal intensity. For the Cy-5 dye, the background signal intensity determined by GenePix was occasionally higher than that of genes that were not highly expressed but that had previously been shown to be differentially expressed (Smart et al. 2003). Therefore, to avoid negative values, we utilized the strategy proposed by Frick and Schaller (2002) and did not subtract the background signal. Data was normalized using the local regression technique, LOWESS (locally weighted scatterplot smoothing), and scale normalization within print-tip groups using the MIDAS software (TIGR). Genes with a $\log _{2}$ of red/green normalized ratio greater than 1.5 standard deviations away from the mean in all the replicates were considered unreliable and were discarded, as previously described (Quackenbush 2002).

Groups of replicates of $\log _{2}$-transformed ratios from each timepoint in the time series were compared for significant differences in mean ratios by using a t-statistic with correction for false-discovery rate as implemented by significance analysis of microarray (SAM) software (Tusher et al. 2001). Briefly, this method assigns a score to each gene on the basis of gene expression relative to the standard deviation of repeated measurements; in this case, measurements for each of five groups $(6,12,24,48$, and 72 h). For genes with scores greater than an adjustable threshold, permutations of the repeated measurements were generated to estimate the percentage of genes identified by chance, the false detection rate. A significant change in gene expression was reported only if the gene was selected by SAM, using combined data from the three experiments.

Cluster analysis was carried out using the Genesis program (version 1.2.2). A nonhierarchical cluster analysis was conducted (k-means clustering). The $\log _{2}$-transformed expression values across all samples were standardized to a mean of 0 and standard deviation of 1 (row standardization). A $\mathrm{k}$ number of eight clusters was chosen after a visual estimation of the number of clusters represented in the data, using principal component analysis as previously described (Quackenbush 2002).

\section{Database submission of microarray data.}

The microarray data were prepared according to MIAME (minimum information about a microarray experiment) recommendations (Brazma et al. 2001) and were submitted to the TIGR potato database, with all files and images for each of the 33 arrays available online.

\section{Rtq-PCR to compare compatible and incompatible interactions.}

Three genes that were identified as highly suppressed during the compatible interaction were chosen to compare gene expression between compatible and incompatible interactions. These genes included 2-ODD (microarray Cluster 7), proteinase inhibitor II (microarray Cluster 1), and CA (microarray Cluster 1).

Total RNA (300 ng), from compatible and incompatible interactions as well as from mock-inoculated plants, was used to generate cDNA, and total transcript levels were determined by rtq-PCR using the ABI PRISM 7000 sequence detection system (Applied Biosystems, Foster City, CA, U.S.A.). Reverse transcription and PCR reactions were carried out in triplicate in 96well plates. Each reaction $(20 \mu \mathrm{l})$ was performed using the Eurogentec one-step RT qPCR kit (Eurogentec North America Inc., San Diego, CA, U.S.A.) and consisted of $1 \times$ reverse transcriptase mix, 1× MasterMix (including Hot Goldstar DNA polymerase), $\mathrm{MgCl}_{2}$ (5 mM final concentration), and dNTPs (200 
$\mu \mathrm{M}$ each dNTP final concentration). Additionally, $300 \mathrm{nM}$ forward and reverse primers and $200 \mathrm{nM}$ probe were added. The primers and probes used for rtq-PCR are shown in Table1.

Following a $30-\mathrm{min}$ reverse transcription step at $48^{\circ} \mathrm{C}, \mathrm{PCR}$ consisted of an initial denaturation step at $95^{\circ} \mathrm{C}$ for $10 \mathrm{~min}$, the amplification occurred in a three-step procedure: $15 \mathrm{~s}$ at $95^{\circ} \mathrm{C}$, $1 \mathrm{~min}$ at $55^{\circ} \mathrm{C}$, and $30 \mathrm{~s}$ at $72^{\circ} \mathrm{C}$, with a total of 45 cycles. Controls lacking reverse transcriptase were included to check for DNA contamination, and controls lacking template were also included.

Transcript levels were calculated using the standard curve method (User Bulletin \#2; ABI PRISM 7700 Sequence Detection System, Applied Biosystems). Standard curves were generated by performing rtq-PCR on serial dilutions of a PCR amplification product of the target gene. Standard curves were constructed by plotting the threshold cycle versus the logarithm of the concentrations. The absolute quantity of the product in each sample was calculated from the standard curves and was normalized against the potato actin gene as an internal control. Reverse transcription rtq-PCR product generated from RNA isolated from mock-inoculated tissue at each timepoint was used as a reference sample. The reference sample was considered to be the $1 \times$ expression level, and results were expressed as the fold increase of mRNA level over the reference sample.

\section{Gene silencing of CA in N. benthamiana.}

Previous studies had generated PVX-virus-induced gene silencing constructs for CA in $N$. benthamiana (Slaymaker et al. 2002). Two cDNA clones (30C84 and 30B10) in a PVX vector and the empty PVX vector control were used in this study. These clones were sequenced at the Cornell University Biotechnology Resource Center to confirm the CA insert. Sequences were then compared with the full-length $N$. tabacum CA gene, using Vector NTI Suite (Invitrogen Bioinformatics, Carlsbad, CA, U.S.A.), and were submitted to GenBank.

Silencing constructs were agro-inoculated according to the methods of Lu and associates (2003). Toothpicks were used to transfer Agrobacterium colonies carrying the appropriate PVX vector construct to $N$. benthamiana plants by making two to three leaf punctures per seedling. Mock-inoculated and empty vector-inoculated plants were included as controls. Systemic PVX infection was observed two to three weeks after inoculation. Individual leaves were then inoculated with $P$. infestans (isolate US970001) and were maintained at $15^{\circ} \mathrm{C}$. For each clone (and the empty vector control), three plants were silenced and, from each plant, two leaves were detached and placed in petri dishes containing moist filter paper, for inoculation with $P$. infestans (for a total of six leaves per silencing construct). The detached leaves were inoculated with 20,000 sporangia per milliliter of $P$. infestans isolate US970001, and leaf disks ( $4 \times 1 \mathrm{~cm}, 40 \mathrm{mg}$ tissue) were collected from each leaf $96 \mathrm{~h}$ after inoculation. Disks were frozen in liquid nitrogen, and total RNA was extracted using the SV RNA isolation kit (Promega, Madison, WI, U.S.A.), following manufacturer's instructions.

\section{RT-PCR to confirm silencing.}

To ensure that the CA gene had been silenced in N. benthamiana plants, RT-PCR was used with primers 5'-CGCCAGCCATA TGGAATTGCAATCATCA-3' (forward) and 5'-CTCGGCGAA TTCGCTTCATACGGAAAGAGA-3' (reverse) (Slaymaker et al. 2002). DNase-treated RNA ( $1 \mu \mathrm{g}$ ) was used for cDNA synthesis, using the iScript cDNA synthesis kit (Bio-Rad, Hercules, CA, U.S.A.), following manufacturer's instructions. PCR was carried out with $2 \mu \mathrm{l}$ of the cDNA synthesis reaction in a $50-\mu \mathrm{l}$ volume containing $0.2 \mathrm{mM}$ each of the four dNTPs, $1 \mu \mathrm{M}$ each of the primers, and $0.5 \mathrm{U} \mathrm{Taq}$ polymerase. PCR conditions consisted of 1 cycle of $95^{\circ} \mathrm{C}$ for $5 \mathrm{~min}$, followed by 35 or 45 cycles of a three-step procedure: $1 \mathrm{~min}$ at $94^{\circ} \mathrm{C}, 1 \mathrm{~min}$ at $55^{\circ} \mathrm{C}$, and $1 \mathrm{~min}$ at $72^{\circ} \mathrm{C}$, and a final step of $5 \mathrm{~min}$ at $72^{\circ} \mathrm{C}$. As a control, RT-PCR of the $N$. benthamiana actin gene was performed with the following primers 5'-AAGACCAGCTCATCCGTG GA-3' and 5'- CTCATCCTATCAGCAATGCCC-3'. The same PCR reaction conditions were used for both $\mathrm{CA}$ and actin.

\section{Quantification of $P$. infestans in $N$. benthamiana.}

Rtq PCR was used to quantify the amount of pathogen present in $N$. benthamiana leaves $96 \mathrm{~h}$ after inoculation with $P$. infestans. Total RNA extracted from a pool of four leaf disks taken from inoculated detached leaves (described above) was also used for $P$. infestans quantification. The ITS region of the pathogen rDNA, GenBank accession number AF266779 (Cooke et al. 2000), was used to generate the rtq-PCR primers and probe listed in Table 1. Conditions for rtq-PCR were as described above, using 45 cycles for pathogen detection. As a control, reverse transcription rtq-PCR was also used to quantify levels of $N$. benthamiana actin cDNA in the same samples. This control enabled quantification of $P$. infestans cDNA per microgram of actin cDNA in each sample. Primers and probe for this gene are also listed in Table 1.

\section{ACKNOWLEDGMENTS}

The authors thank H. W. Lange, H. S. Mayton, and N. Zhang for technical assistance. This work was supported, in part, by the New York State Agricultural Experiment Station (C. D. Smart), and National Science Foundation grants DBI-9975866 (W. E. Fry and C. R. Buell) and DBI0116076 (G. B. Martin).

\section{LITERATURE CITED}

Avrova, A. O., Taleb, N., Rokka, V., Heilbronn, J., Campbell, E., Hein, I., Gilroy, E. M., Cardle, L., Bradshaw, J. E., Stewart, H. E., Fakim, Y. J., Loake, G. J., and Birch, P. R. J. 2004. Potato oxysterol binding protein and cathepsin $\mathrm{B}$ are rapidly up-regulated in independent defense pathways that distinguish $R$ gene-mediated and field resistances to Phytophthora infestans. Mol. Plant Pathol. 5:45-56.

Avrovra, A. O., Stewart, H. E., De Jong, W., Heilbronn, J., Lyon, G. D., and Birch, P. R. J. 1999. A cysteine protease gene is expressed early in resistant potato interactions with Phytophthora infestans. Mol. PlantMicrobe Interact. 12:1114-1119.

Becktell, M. C. 2005. The host-pathogen interactions and epidemiological implications of the Petunia x hybrida, Calibrachoa hybridus and Nicotiana benthamiana-late blight systems. Ph.D thesis. Cornell University, Ithaca, NY, U.S.A.

Beyer, K., Binder, A., Boller, T., and Collinge, M. 2001. Identification of potato genes induced during colonization by Phytophthora infestans. Mol. Plant Pathol. 2:125-134.

Birch, P. R. J., Avorva, A. O., Duncan, J. M., Lyon, G. D., and Toth, R. L. 1999. Isolation of potato genes that are induced during an early stage of the hypersensitive response to Phytophthora infestans. Mol. PlantMicrobe Interact. 12:356-361.

Brazma, A., Hingamp, P., Quackenbush, J., Sherlock, G., Spellman, P., Stoeckert, C., Aach, J., Ansorge, W., Ball, C. A., Causton, H. C., Gaasterland, T., Glenisson, P., Holstege, F. C. P., Kim, I. F., Markowitz, V., Matese, J. C., Parkinson, H., Robinson, A., Sarkans, U., SchulzeKremer, S., Stewart, J., Taylor, R., Vilo, J., and Vingron, M. 2001. Minimum information about a microarray experiment (MIAME) Toward standards for microarray data. Nature Genet. 29:365-371.

Burnell, J. N. 2000. Carbonic anhydrases of higher plants: An overview. Pages 501-518. in: The Carbonic Anhydrases: New Horizons. W. R. Chegwidden, N. D. Carter, and Y. H. Edwards, eds. Birkhauser Verlag, Basel.

Coffey, M. D., and Wilson, U. E. 1983. An ultrastructural study of the lateblight fungus Phytophthora infestans and its interaction with the foliage of two potato cultivars possessing different levels of general (field) resistance. Can. J. Bot. 61:2669-2685.

Cooke, D. E. L., Drenth, A., Duncan, J. M., Wagels, G., and Brasier, C. M. 2000. A molecular phylogeny of Phytophthora and related oomycetes. Fungal Genet. Biol. 30:17-32.

Dellagi, A., Heilbronn, J., Avrova, A. O., Montesano, M., Palva, E. T., Stewart, H. E., Toth, I. K., Cooke, D. E. L., Lyon, G. D., and Birch, P. 
R. J. 2000. A potato gene encoding a WRKY-like transcription factor is induced in interactions with Erwinia carotovora subsp. atroseptica and Phytophthora infestans and is coregulated with class I endochitinase expression. Mol. Plant-Microbe Interact. 13:1092-1101.

Doke, N., Sanchez, L. M., Yoshioka, H., Kawakita, K., Miura, Y., and Park, H.-J. 1998. The oxidative burst system in plants: A strategic signal transduction system for triggering active defense and for parasites to overcome. Pages 331-341 in: Molecular Genetics of Host-Specific Toxins in Plant Disease. K. Kohmoto and O. C. Yoder, eds. Kluwer Academic Publishers, Dordrecht, The Netherlands.

Fidantsef, A. L., Stout, M. J., Thaler, J. S., Duffey, S. S., and Bostock, R. M. 1999. Signal interactions in pathogen and insect attack: Expression of lipoxygenase, proteinase inhibitor II, and pathogenesis-related protein P4 in the tomato, Lycopersicon esculentum. Physiol. Mol. Plant Pathol. 54:97-114.

Freytag, S., Arabatizis, N., Hahlbroock, K., and Schmelzer, E. 1994. Reversible cytoplasmic rearrangements precede wall apposition, hypersensitive cell death and defense-related gene activation in potato/ Phytophthora infestans interactions. Planta 194:123-135.

Frick, U. B., and Schaller, A. 2002. cDNA microarray analysis of fusicoccin-induced changes in gene expression in tomato plants. Planta 216:83-94.

Gebhardt, C., and Valkonen, J. P. T. 2001. Organization of genes controlling disease resistance in the potato genome. Annu. Rev. Phytopathol. 39:79-102.

Gibly, A., Bonshtien, A., Balaji, V., Debbie, P., Martin, G. B., and Sessa, G. 2004. Identification and expression profiling of tomato genes differentially regulated during a resistance response to Xanthomonas campestris pv. vesicatoria. Mol. Plant-Microbe Interact. 17:1212-1222.

Goodwin, S. B., Smart, C. D., Sandrock, R. W., Deahl, K. L., Punja, Z. K., and Fry, W. E. 1998. Genetic change within populations of Phy tophthora infestans in the United States and Canada during 1994 to 1996: Role of migration and recombination. Phytopathology 88:939949

Gu, Y., Yang, C., Thara, V. K., J., Z., and Martin, G. B. 2000. The Pti4 gene is regulated by ethylene and salicylic acid and its product is phosphorylated by the Pto kinase. Plant Cell 12:771-785.

Hausinger, R. P. 2004. Fe(II)/alpha-ketoglutarate-dependent hydroxylases and related enzymes. Crit. Rev. Biochem. Mol. 39:21-68.

Hedge, P., Qi, R., Abernathy, K., Gay, C., Dharap, S., Gaspard, R., Hughes, J. E., Snesrud, E., Lee, N., and Quackenbush, J. 2000. A concise guide to cDNA microarray analysis. BioTechniques 29:548-562.

Hoang, C. V., and Chapman, K. D. 2002. Biochemical and molecular inhibition of plastidial carbonic anhydrase reduces the incorporation of acetate into lipids in cotton embryos and tobacco cell suspensions and leaves. Plant Physiol. 128:1417-1427.

Huitema, E., Vleeshouwers, V. G. A. A., Francis, D. M., and Kamoun, S 2003. Active defense responses associated with non-host resistance of Arabidopsis thaliana to the oomycete pathogen Phytophthora infestans. Mol. Plant Pathol. 4:487-500.

Jin, U.-H., Lee, J.-W., Chung, Y.-S., Lee, J.-H., Yi, Y.-B., Kim, Y.-K., Hyung, N.-I., Pyee, J.-H., and Chung, C.-H. 2001. Characterization and temporal expression of an omega-6 fatty acid desaturase cDNA from sesame (Sesamun indicum L.) seeds. Plant Sci. 161:935-941.

Koch, C., Noga, G., and Strittmatter, G. 1994. Photosynthetic electron transport is differentially affected during early stages of cultivar/racespecific interactions between potato and Phytophthora infestans. Planta 193:551-557.

Kolomiets, M. V., Chen, H., Gladon, R. J., Braun, E. J., and Hannapel, D. J. 2000. A leaf lipoxygenase of potato induced specifically by pathogen infection. Plant Physiol. 124:1121-1130.

Lantin, S., O'Brien, M., and Matton, D. P. 1999. Pollination, wounding and jasmonate treatments induce the expression of a developmentally regulated pistil dioxygenase at a distance, in the ovary, in the wild potato Solanum chacoense. Plant Mol. Biol. 41:371-386.

Lu, R., Martin-Hernandez, A. M., Peart, J. R., Malcuit, I., and Baulcombe, D. C. 2003. Virus-induced gene silencing in plants. Methods 30:296-303.

Matsumura, H., Reich, S., Ito, A., Saitoh, H., Kamoun, S., Winter, P., Kahl, G., Reuter, M., Kruger, D. H., and Terauchi, R. 2003. Gene ex- pression analysis of plant host-pathogen interactions by SuperSAGE. Proc. Natl. Acad. Sci. U.S.A. 100:15718-15723.

Moy, P., Qutob, D., Chapman, B. P., Atkinson, I., and Gijzen, M. 2004. Patterns of gene expression upon infection of soybean plants by Phytophthora sojae. Mol. Plant-Microbe Interact. 17:1051-1062.

Mysore, K. S., Crasta, O. R., Tuori, R. P., Folkerts, O., Swirsky, P. B., and Martin, G. B. 2002. Comprehensive transcript profiling of Pto- and Prfmediated host defense responses to infection by Pseudomonas syringae pv. tomato. Plant J. 32:299-315.

Perry, K. L., and Francki, R. I. B. 1992. Insect-mediated transmission of mixed and reassorted cucumovirus genomic RNAs. J. Gen. Virol 73:2105-2114.

Price, G. D., von Caemmerer, S., Evans, J. R., Yu, J. W., Lloyd, J., Oja, V., Kell, P., Harrison, K., Gallagher, A., and Badger, M. R. 1994. Specific reduction of chloroplast carbonic anhydrase activity by antisense RNA in transgenic tobacco plants has a minor effect on photosynthetic $\mathrm{CO} 2$ assimilation. Planta 193:331-340.

Quackenbush, J. 2002. Microarray data normalization and transformation. Nature Genet. Supplement S 32:496-501.

Ronning, C. M., Stegalkina, S. S., Ascenzi, R. A., Bougri, O., Hart, A. L., Utterbach, T. R., Vanaken, S. E., Riedmuller, S. B., White, J. A., Cho, J., Pertea, G. M., Lee, Y., Karamycheva, S., Sultana, R., Tsai, J., Quackenbush, J., Griffiths, H. M., Restrepo, S., Smart, C. D., Fry, W. E., Van Der Hoeven, R., Tanksley, S., Zhang, P., Jin, H., Yamamoto, M. L., Baker, B. J., and Buell, C. R. 2003. Comparative analyses of potato expressed sequence tag libraries. Plant Physiol. 131:419-429.

Schenk, P. M., Kazan, K., Wilson, I., Anderson, J. P., Richmond, T., Somerville, S. C., and Manners, J. M. 2000. Coordinated plant defense responses in Arabidopsis revealed by microarray analysis. Proc. Natl. Acad. Sci. U.S.A. 97:11655-11660.

Schnabel, G., Strittmatter, G., and Noga, G. 1998. Changes in photosynthetic electron transport in potato cultivars with different field resistance after infection with Phytophthora infestans. J. Phytopathol. 146:205-210.

Slaymaker, D. H., Navarre, D. A., Clark, D., del Pozo, O., Martin, G. B., and Klessig, D. F. 2002. The tobacco salicylic acid-binding protein 3 (SABP3) is the chloroplast carbonic anhydrase, which exhibits antioxidant activity and plays a role in the hypersensitive defense response. Proc. Natl. Acad. Sci. U.S.A. 99:11640-11645.

Smart, C. D., Willmann, M. R., Mayton, H., Mizubuti, E. S. G., Sandrock, R. W., Muldoon, A. E., and Fry, W. E. 1998. Self-fertility in two clonal lineages of Phytophthora infestans. Fungal Genet. Biol. 25:134-142.

Smart, C. D., Hodge, K. T., Haney, C. H., and Fry, W. E. 2002. Comparison of elicitin genes in closely related Phytophthora species. Phytopathology 92:S77.

Smart, C. D., Myers, K. L., Restrepo, S., Martin, G. B., and Fry, W. E. 2003. Partial resistance of tomato to Phytophthora infestans is not dependent upon ethylene, jasmonic acid, or salicylic acid signaling pathways. Mol. Plant-Microbe Interact. 16:141-148.

Tusher, V. G., Tibshirani, R., and Chu, G. 2001. Significance analysis of microarrays applied to the ionizing radiation response. Proc. Natl. Acad. Sci. U.S.A. 98:5116-5121.

Vleeshouwers, V. G. A. A., van Dooijeweert, W., Govers, F., Kamoun , S., and Colon, L. T. 2000. The hypersensitive response is associated with host and nonhost resistance to Phytophthora infestans. Planta 210:853-864.

Yoshioka, H., Yamada, N., and Doke, N. 1999. cDNA Cloning of sesquiterpene cyclase and squalene synthase, and expression of the genes in potato tuber infected with Phytophthora infestans. Plant Cell Physiol. 40:993-998.

\section{AUTHOR-RECOMMENDED INTERNET RESOURCES}

Graz University of Technology, Institute for Genomics and Bioinformatics Genesis program: genome.tugraz.at

The Institute for Genomic Resources (TIGR) NSF potato functional genomics and solanaceae resources website: www.tigr.org/tdb/potato

Microarray data (TIGR database) ftp://ftp.tigr.org/pub/data/s_tuberosum/SGED/062_Restrepo/

TIGR Midas software: www.tigr.org/software/tm4/midas.html 